\title{
An empirical enquiry into windows used in tropical office spaces
}

\author{
Gyimah K. A. *, Amos-Abanyie S.
}

\author{
Department of Architecture, College of Art and Built Environment, Kwame Nkrumah University of Science and \\ Technology, Ghana. \\ * Corresponding Author: kobbygyimah@gmail.com
}

Received: 28-06-2018

Revised: 20-12-2018

Accepted: 18-12-2018

\begin{abstract}
Environmental health is very instrumental to the survival of the human race and there is the need for behavioural change for its quality. Grounded in literature is the fact that amongst all the elements of the building fabric, window is the only element which contributes holistically to Indoor Environmental Quality (IEQ). However, there is no certainty that building professionals or clients consider IEQ in the selection of windows for buildings and spaces holistically. This study seeks to evaluate the various types of windows mostly used in office spaces and establish the rational for their choice. Questionnaires in the form of Google forms were developed and sent to a convenient sampled population of architects and clients in Ghana. Results shows that none of the architects or clients choice of window had a holistic rational towards achieving all the variables of IEQ - thermal comfort, lighting quality, air quality and sound quality. Most of the choices by respondents were based on at least one of the variables of IEQ as a rational. In some cases, the rational of clients had no link to IEQ. Both clients and professionals suggested modifications to current office windows for better IEQ. It is also recommended that further research is carried out to validate the findings. The relevance of this study cannot be down played as knowledge is acquired for re-engineering of appropriate and holistic window towards IEQ.
\end{abstract}

Key words: Environmental health, Indoor environmental quality, Offices, Tropics, Windows Constructions.

\section{Introduction}

The $21^{\text {st }}$ century is fluxed with various organisations and institutions with the aim of solving problems of man to make life better. Life improvement is always evident in the development of the society, country or world at large. However, this cannot be realised if high levels of productivity are not achieved in our institutions responsible for specific task. Higher productivity has a direct link to occupants being comfortable in the spaces they work in. To Chua et al. (2016), "the physical environment comfort in a workplace is claimed to be vital as it will encourage healthier, more productive and lower absenteeism rate among employees". Employee turnover rate is also reduced as a result of high comfort levels. Therefore companies should invest into developing high user comforts to yield better results (Feige et al, 2013).

The link of IEQ to comfort, health and productivity cannot be disputed as researchers like Mahbob et al., (2011); Huizenga et al., (2006); Abbaszadeh et al., (2006) and Moschandreas (1998) have established it in their studies.

For total comfort to be achieved in indoor spaces, Indoor Environmental Quality (IEQ) must be achieved in spaces. IEQ is achieved when thermal comfort, acoustic comfort, lighting comfort and air comfort are achieved (REHVA, 2010; Bluyssen, 2009; Dascalaki et al., 2009). REHVA (2010) further explains the inter relationship between IEQ and other factors as in Figure 1. 


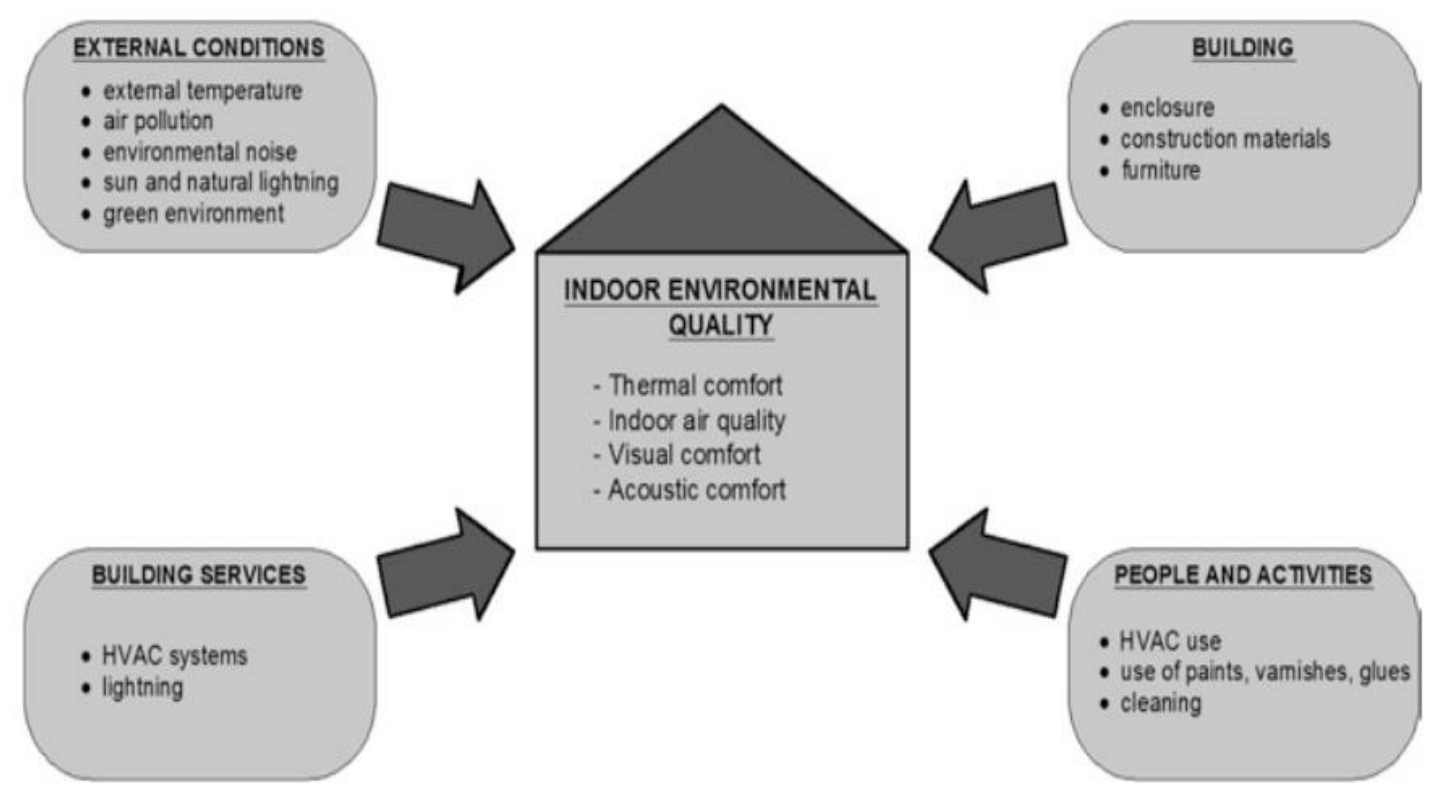

Fig 1. Inter relationship between IEQ and other factors (REHVA, 2010)

Leaman (1995) reports that space users who are not happy with lighting levels, air quality, temperature and noise conditions have effects on their productive levels. This then establishes the need for a holistic IEQ in all indoor spaces. One key element of the building fabric that contributes naturally for a holistic IEQ to be achieved is windows (Gyimah et al., 2017). There are various windows across the globe used for different purposes. According to the Singapore Building and Construction Authority (SBCA), the tropics is characterised by different kinds of windows and some notable ones are top or bottom hung, casement and louvers (SBCA, 2016). Figure 2 exhibits some windows used in the tropics for specific IEQ level.

Sliding Window

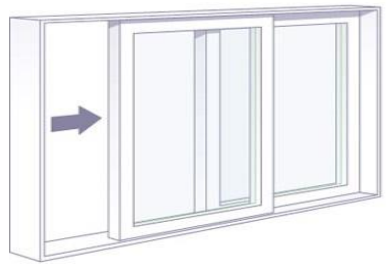

Double Hung

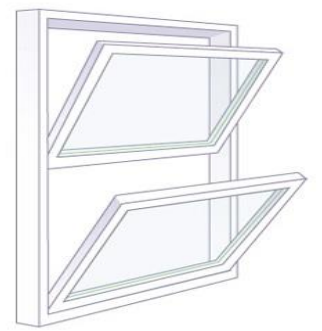

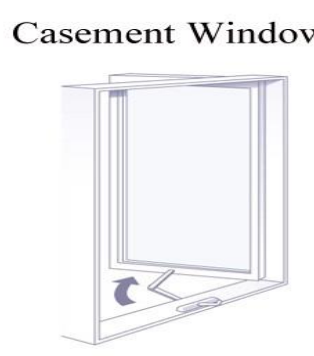

Fixed Window

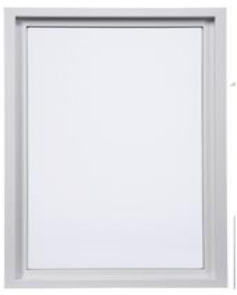

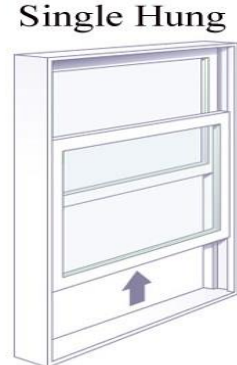

Awning Window

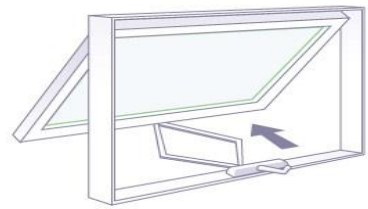

Louvre

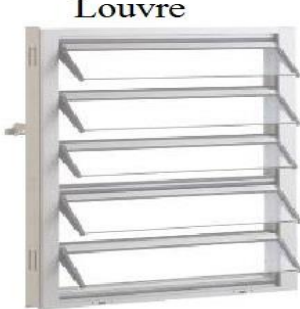

Centre Pivot

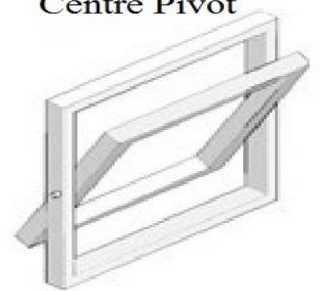

Fig 2. Different windows styles (Source: aluminiumwindows.com; sideshare.net) 
The different windows styles in Figure 2 have specific contribution to IEQ levels within a space. Some are for air quality whiles others are for thermal quality and thus care must be taken when choosing any. Air quality is achieved through ventilation by windows introducing fresh air into spaces (Persram et al., 2007); lighting quality is realised through windows allowing natural day light into spaces (Barrett et al., 2012); heat influx for discomfort can be reduced through windows with Phase Change Materials (Alawadhi, 2012); noise pollution is minimised through closed windows (Koranteng et al., 2016).

These studies above have shown that tropical windows play a key to IEQ, but no known research into tropical windows presents a holistic solution to IEQ. As one part of IEQ is achieved, the other suffers and therefore space users are struggling to have a total IEQ. There is therefore the need for further research to re-engineer tropical office windows for a holistic IEQ (Gyimah et al., 2017).

According to Hammer and Champy (2006) re-engineering cannot be achieved without asking the questions: "why do we do what we do? and why do we do it the way we do?" This means that there is the need to know what is done, why that is done and why is it done that way. Questions thus formulated to deal with windows re-engineering in the tropics are: which window type is used for tropical offices? and what is the rationale behind the choice of these windows?

This study seeks to establish window types used for topical office spaces and the rationale behind its choice. The objectives set to achieve aim and thus answer questions asked are: to establish window(s) used for tropical office spaces, to know the rationale behind the choice of tropical office windows and make recommendations to guide the re-engineering tropical office windows. Knowledge of the type(s) of windows specifically used for office spaces will help to narrow the scope of window re-engineering. The theory of reductionism comes into play here and as explained by Mandik (2013), it gives a clearer answer to the question of correlation. These clearer answers will help guide the process of re-engineering. The relevance of this study cannot be down played as knowledge will be acquired for re-engineering of appropriate and holistic window towards IEQ.

\section{Materials and Methods}

The research design for this study was mixed and used both qualitative and quantitative approaches. Quantitative aspects dealt with the use of descriptive frequencies and percentages for data analysis. Qualitatively, phenomenology is the key philosophy that drives this study. Phenomenology as a philosophy deals with knowledge from a person's point of view on a particular object based on first hand experiences (Gyimah et al., 2017).

These experiences are intentionally sought within a specific scope to understand situations. Therefore the use of phenomenology for this study is to know the rationale behind the choice of various windows based on their experiences.

The bottom-up approach was used to sample out a unit thus normal office users, then professionals (Architects). Sample method convenient sampling due to time constraints. 120 users and 80 architects totalling 200 respondents were sampled as the size for this study. The research tool used for data collection was questionnaire (Google forms). Most questionnaires were used open ended questions and thus more qualitative data was collected and analysed.

\section{Results and discussion}

Data realised from questionnaires totalled 129 of the sample size of 200 , representing $64.5 \%$ response rate. With response rate over $50 \%$, analysis were done for results and discussions. 


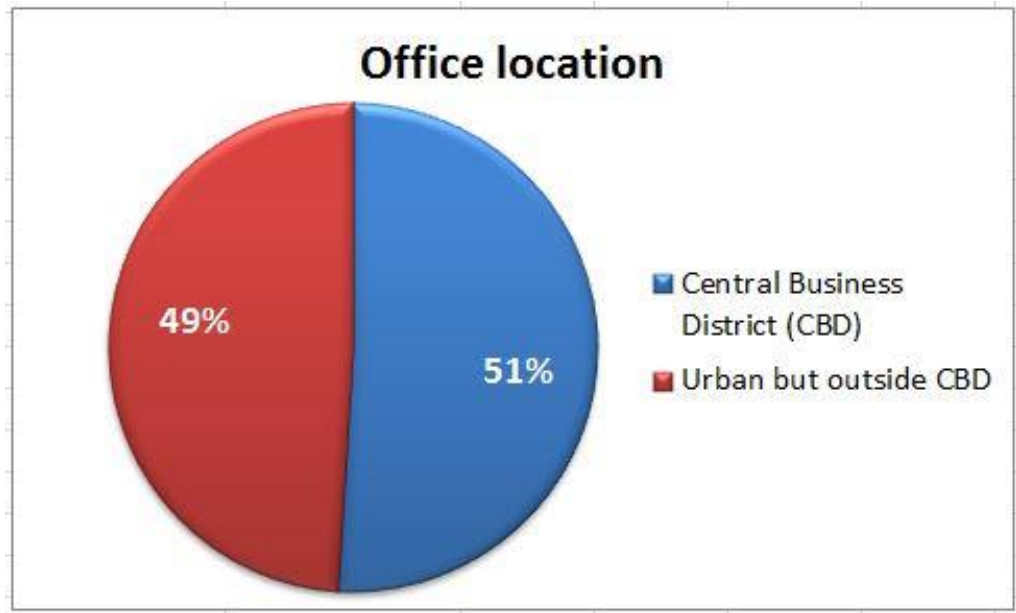

Fig 3. Office location of respondents

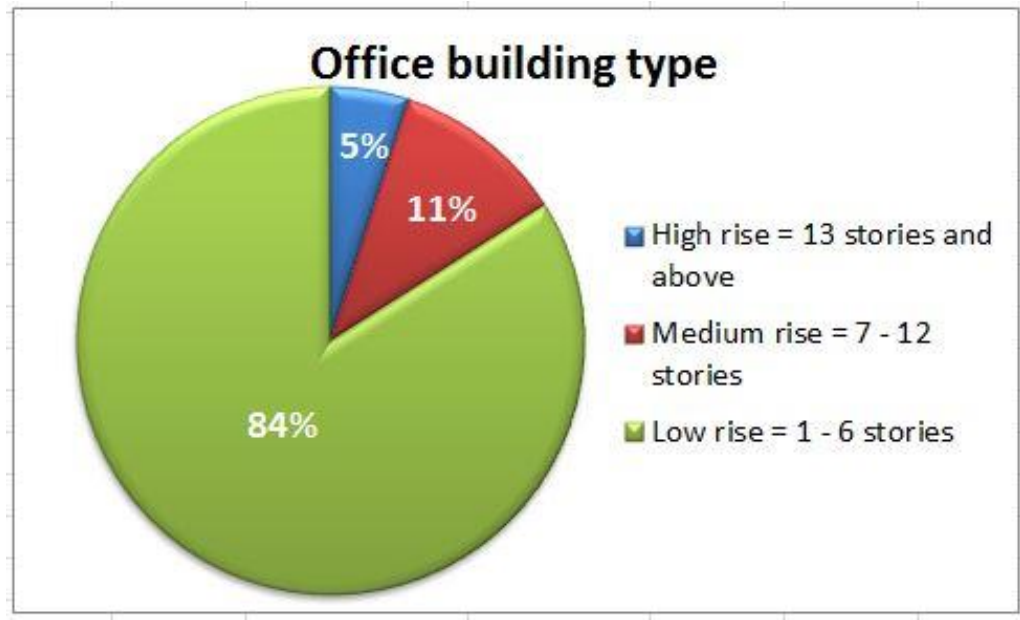

Fig 4. Office type used or design by respondents

From Figure 3 and 4, most offices are low rise and found in the Central Business District (CBD) and thus noise pollution can have effect on office spaces. Sound influx into a building is however determined by the building enclosure especially windows used. Data collected on windows used for office spaces depicts a higher number of respondents using sliding windows as in Figure 5.

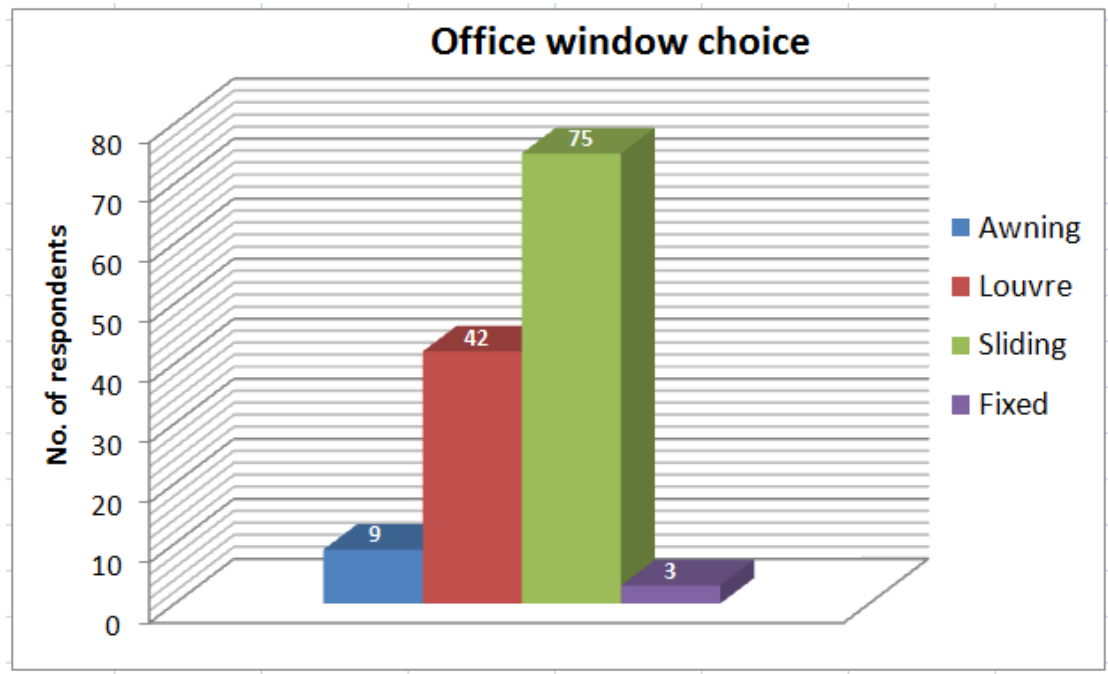

Fig 5. Office window type used or designed by respondents 
Interestingly, Table 1 shows sliding windows performance to IEQ as weak but has other attributes such as elegance, corporate and modern. Awning which performs better towards IEQ however has low usage. Therefore further research is needed to understand this development.

Table 1. Rationale for office window choice

\begin{tabular}{|c|c|c|c|c|c|}
\hline & $\begin{array}{l}\text { Lighting } \\
\text { quality }\end{array}$ & Air quality & $\begin{array}{l}\text { Thermal } \\
\text { comfort }\end{array}$ & Sound quality & Others \\
\hline Awning & $\begin{array}{c}\text { Good natural } \\
\text { lighting }\end{array}$ & $\begin{array}{c}\text { Good natural } \\
\text { ventilation }\end{array}$ & $\begin{array}{c}\text { Thermally } \\
\text { comfortable }\end{array}$ & $\begin{array}{c}\text { Sound } \\
\text { proofing when } \\
\text { closed }\end{array}$ & Aesthetics \\
\hline Louver & $\begin{array}{c}\text { Good natural } \\
\text { lighting }\end{array}$ & $\begin{array}{c}\text { Good natural } \\
\text { ventilation }\end{array}$ & $\begin{array}{c}\text { Thermally } \\
\text { comfortable }\end{array}$ & $\begin{array}{c}\text { Not sound } \\
\text { proof }\end{array}$ & $\mathrm{N} / \mathrm{A}$ \\
\hline Sliding & $\begin{array}{l}\text { Good natural } \\
\text { lighting }\end{array}$ & $\begin{array}{l}\text { Not Good for } \\
\text { natural } \\
\text { ventilation }\end{array}$ & $\begin{array}{l}\text { Not thermally } \\
\text { comfortable }\end{array}$ & $\begin{array}{c}\text { Sound } \\
\text { proofing when } \\
\text { closed }\end{array}$ & $\begin{array}{c}\text { Aesthetics, } \\
\text { Elegance, } \\
\text { Modern } \\
\text { Corporate }\end{array}$ \\
\hline Fixed & $\begin{array}{l}\text { Good natural } \\
\text { lighting }\end{array}$ & $\begin{array}{c}\text { Not Good for } \\
\text { natural } \\
\text { ventilation }\end{array}$ & $\begin{array}{l}\text { Not thermally } \\
\text { comfortable }\end{array}$ & $\begin{array}{l}\text { Sound } \\
\text { proofing }\end{array}$ & Aesthetics \\
\hline
\end{tabular}

Sliding windows is challenged with thermal comfort and natural ventilation whiles louvers has a challenge with sound proofing. However, awning which seem not to have major issues with IEQ is the least patronised by users and architects. Therefore an argument can be made that clients and architects do not holistically take into consideration IEQ when choosing windows. Since majority of windows currently used in office spaces does not achieve IEQ, 53\% of respondents are of the view that modifications are needed on existing office windows for better IEQ (Figure 6). Table 2 presents various recommendations outlined by respondents on windows for better IEQ.

\section{Modify current office windows}

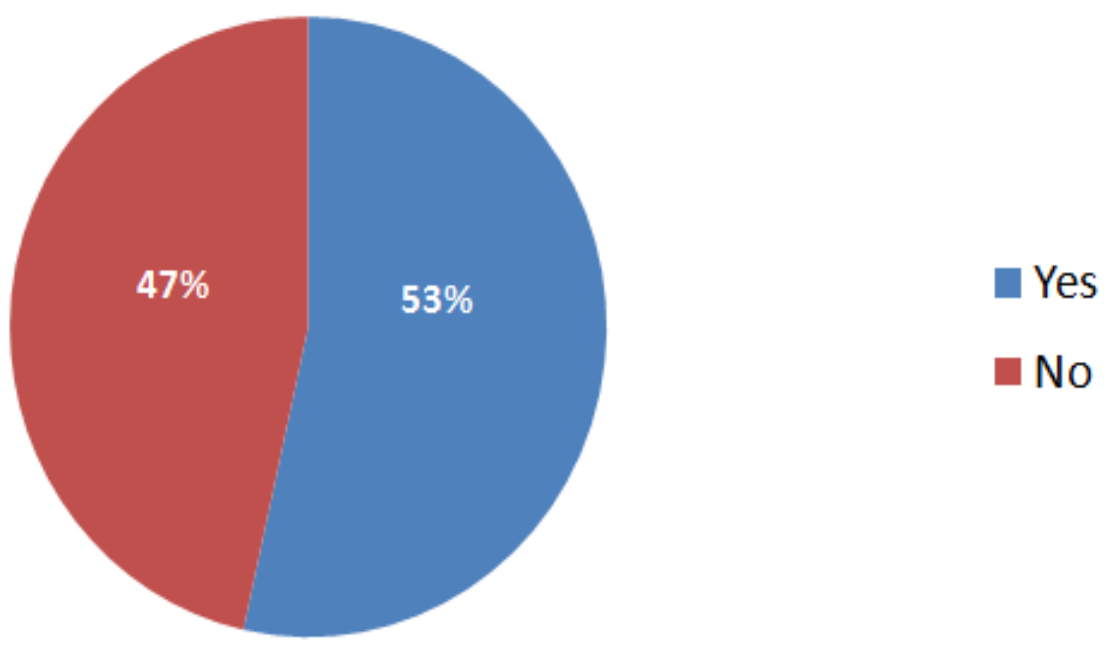

Fig 6. Modification of current office windows 
Table 2. Recommended modifications from respondents

\begin{tabular}{|c|c|}
\hline Window & Recommendation from respondents \\
\hline \hline Awning & $\mathrm{N} / \mathrm{A}$ \\
\hline Louver & Sound proofing qualities should be inculcated \\
\hline Sliding & $\begin{array}{r}\text { Bigger windows for better natural ventilation } \\
\text { Hybrid of louver and sliding } \\
\end{array}$ \\
\hline Fixed & Should be operable glass thickness for better sound proofing \\
\hline
\end{tabular}

\section{Conclusions}

Study has shown that no window has been able to holistically achieve IEQ. Sliding windows which is the predominantly used needs some modifications for total IEQ. Louvers which is ranked second to sliding need to have sound proofing properties. Awning with its low usage seems to perform better when it comes to IEQ. An argument can thus be made that clients and architects don't holistically take into consideration IEQ when choosing windows. The following recommendations are therefore given to guide window choice for holistic IEQ:

- Window show be operable and big enough to allow for natural lighting and ventilation

- When a window is closed, it should be air tight to prevent infiltration

- Window thickness should be increase for better sound proofing

Further research is however recommended to physically measure the performance of these windows either to confirm or debunk these findings before re-engineering.

\section{Acknowledgements}

This paper is part of a PhD thesis at the Department of Architecture, Kwame Nkrumah University of Science and Technology. Appreciation goes to the College of Engineering of the Kwame Nkrumah University of Science and Technology for the opportunity to present this research at the Conference on Engineering, Science, Technology, and Entrepreneurship (ESTE 2015)

\section{References}

Abbaszadeh, S., Zagreus, L., Lehrer, D., \& Huizenga, C. (2006). Occupant satisfaction with indoor environmental quality in green buildings. Proceedings, Healthy Buildings, 3, 365-370

Alawadhi, E. M. (2012). Using phase change materials in window shutter to reduce the solar heat gain. Energy and Buildings, 47, 421-429.

Barrett, P., Zhang, Y., Moffat, J., \& Kobbacy, K. (2013). A holistic, multi-level analysis identifying the impact of classroom design on pupils' learning. Building and Environment, 59, 678-689.

Bluyssen, P. (2009). The Indoor Environment Handbook: How to Make Buildings Healthy and Comfortable. Routledge. London, Earthscan.

Chua, S. J. L., Ali, A. S., \& Lim, M. E. L. (2016). Physical environment comfort impacts on office employee's performance. In MATEC Web of Conferences (Vol. 66, p. 00124). EDP Sciences.

Dascalaki, E. G., Gaglia, A. G., Balaras, C. A., \& Lagoudi, A. (2009). Indoor environmental quality in Hellenic hospital operating rooms. Energy and Buildings, 41(5), 551-560.

Feige, A., Wallbaum, H., Janser, M., \& Windlinger, L. (2013). Impact of sustainable office buildings on occupant's comfort and productivity. Journal of Corporate Real Estate, 15(1), 7-34.

Gyimah, K. A., Amos - Abanyie, S. and Kootin - Sanwu, V. (2017) The importance of windows in attaining Indoor Environmental Quality in the tropics: A review. In Ayarkwa J., Ahadzie D. K., Adinyira E., 
Kwofe T. and Owusu-Manu D., paper presented at the $6^{\text {th }}$ International Conference on Infrastructure Development in Africa (ICIDA) (pp 358 - 367). Kumasi, Ghana, College of Art and Built Environment, KNUST.

Hammer, M. and Champy, J. (2006). Reengineering the Corporation: A Manifesto for Business Revolution, Harper Collins Publishers, New York

Huizenga, C., Abbaszadeh, S., Zagreus, L., \& Arens, E. A. (2006). Air quality and thermal comfort in office buildings: results of a large indoor environmental quality survey. Proceedings, Healthy Buildings, 3 , 393-397

Koranteng, C., Amos-Abanyie, S., \& Kwofie, T. E. (2016). Environmental Noise Exposure On Occupants In Naturally Ventilated Open-Plan Offices: Case Of Selected Offices In Kumasi, Ghana, International Journal of Scientific \& Technology Research 5(10) 138-146

Leaman, A. (1995). Dissatisfaction and office productivity. Facilities, 13(2), 13-19.

Mahbob, N. S., Kamaruzzaman, S. N., Salleh, N., \& Sulaiman, R. (2011). A correlation studies of indoor environmental quality (IEQ) towards productive workplace, $2^{\text {nd }}$ International Conference on Environmental Science and Technology, 2, 434- 438.

Mandik, P. (2013). This is philosophy of mind: An introduction, John Wiley \& Sons, Vol. 22.

Moschandreas, D. J. (Ed.). (1998). Design, Construction, and Operation of Healthy Buildings: Solutions to Global and Regional Concerns. Ashrae, USA.

Persram, S., Lucuik, M., \& Larsson, N. (2007). Marketing green buildings to tenants of leased properties. Canada Green Building Council.

SBCA (2016). Singapore Building and Construction Authority, Accessed 02/09/16 at https://www.bca.gov.sg/professionals/iquas/..\%5CIquas\%5Cgpgs\%5CAWindow\%5CAWDesign.pdf 